\section{Cervical ripening methods for labor induction}

\section{Métodos de preparo cervical para indução do trabalho de parto}

Fernanda Garanhani de Castro Surita 1

José Guilherme Cecatti 2

Fabiana Kruppa 3

Ricardo Porto Tedesco 4

Mary Ângela Parpinelli 5

1-3,5 Departamento de Tocoginecologia. Faculdade de Ciências Médicas. Universidade Estadual de Campinas. Rua Alexandre Flemming, 101. CEP: 13.084-881 Campinas, SP, Brasil. E-mail:surita@unicamp.br

4 Departamento de Ginecologia e Obstetrícia. Faculdade de Medicina de Jundiaí. Jundiaí, SP, Brasil.

\begin{abstract}
The indication for labor induction has been increasing in the world. It is known that cervical conditions are directly associated to the success of labor induction. Knowledge of cervix anatomy and physiology during pregnancy and of the different methods for cervical ripening is essential for indicating the best cervical ripening method in a given situation, therefore obtaining the best outcomes following labor induction. This is a challenge for obstetricians where not every method is readily available and accessible and $C$-sections rates are very high as in Brazil. Some methods are discussed in this paper including breast stimulation, membrane stripping, and the use of relaxin, oxytocin, prostaglandins, hyaluronidase, mifepristone, laminaria and Foley catheter.
\end{abstract}

Key words Parturition, Prostaglandins, Hyaluronoglucosaminidase
Resumo Tem sido mundialmente crescente a indicação de indução do trabalho de parto. Sabe-se que as condições do colo uterino estão diretamente relacionadas com o sucesso da indução. O conhecimento da anatomia e fisiologia do colo uterino durante a gestação, bem como as dos diversos métodos de preparo cervical, são de fundamental importância para que possa ser indicado o melhor método para o preparo de colo em uma situação específica e conseqüentemente obter-se melhores resultados nas induções do trabalho de parto. Esse é um desafio para os obstetras de um país em que nem todos os métodos estão disponíveis e acessíveis e com taxas de cesarianas tão elevadas quanto o Brasil. São discutidos alguns métodos incluindo a estimulação dos mamilos, descolamento de membranas, relaxina, ocitocina, prostaglandinas, hialuronidase, mefiprestone, laminaria e sonda Foley.

Palavras-chave Parto, Prostaglandinas, Hialuronoglucosaminidase 


\section{Introduction}

The progress of Medicine in general and of Obstetrics in particular has allowed for more high risk pregnancies to evolve to term or close to term, with maternal or fetal pregnancy interruption before the onset of spontaneous labor. This associated to the fact that vaginal delivery has become the best choice for women and health professionals ${ }^{1}$ has created the growing need to induce labor in women with unripe cervices.

Labor induction in unfavorable cervix conditions is a difficult and lengthy procedure, extenuating for both mother and obstetrician. Many times it may fail and this outcome can be frustrating for both. Therefore, in the face of a situation indicating pregnancy interruption it is fundamental to assess the cervix conditions to predict induction success. Vaginal exam to assess the cervix may be an extremely subjective procedure and for this reason systematic methods to evaluate and standardize procedures in the case of need for cervical ripening and/or labor induction were created.
In the sixties, Bishop 2 published the results of a study establishing labor induction prognosis through the assessment of five specific factors determined during vaginal exam: cervix dilation, effacement, consistency and position of the cervix and fetal descent. Values from zero to two for cervix consistency and position, from zero to three for the other factors are attributed. Considering that four of these parameters refer to the cervix, it is the fundamental component of the zero to thirteen score determining ripeness. He additionally concluded that induction in women with a score over eight was successful in the great majority of cases. The Bishop Index represented a great contribution to Obstetrics. Although other scores or modifications of the Bishop Index were created, it remains in use because it is easy to apply and also efficient in evaluating the degree of cervical ripeness and establishing prognosis for elective labor induction (Table 1). Therefore, when labor induction is performed, a favorable cervix is fundamental to a good outcome as well as an adequate cervical ripening procedure, when cervix is unripe.

Table 1

Bishop's Index

\begin{tabular}{|c|c|c|c|c|}
\hline \multirow{2}{*}{ Parameters } & \multicolumn{4}{|c|}{ Score } \\
\hline & 0 & 1 & 2 & 3 \\
\hline Dilatation $(\mathrm{cm})$ & 0 & $1-2$ & $3-4$ & $5-6$ \\
\hline Effacement (\%) & $0-30$ & $40-50$ & $60-70$ & $>70$ \\
\hline Fetal descent & -3 & -2 & $-1,0$ & $+1,+2$ \\
\hline Cervix position & posterior & median & anterior & \\
\hline
\end{tabular}

Fonte: Bishop EH. Pelvic scoring... Obstet precol 1964.2

Theoretically the ideal method for cervical ripening would be a non-invasive method causing the same physiological changes in the cervix, i.e. effacement and softening without uterine contractility compatible with active labor. ${ }^{3}$ Nevertheless, it is known that ideal conditions are difficult to obtain with the use of a stand-alone product, although some methods do come closer to being ideal, but all may potentially onset parturition, especially when used in at term or post-term pregnancies. The difference between cervical ripening and labor induction is many times difficult, almost artificial, depending, on the method used, if only one dose or more than one drug or increased ministration time of a specific agent. ${ }^{3}$

\section{Anatomy and physiology of the cervix during pregnancy and labor}

The uterus and cervix originate from the synthesis of the distal portion of müllerian ducts followed by the 
central absorption of tissue of the same origin. The cervix is formed by and extra cellular matrix of conjunctive tissue comprised by type I, III and IV collagen and only $10 \%$ to $15 \%$ of muscle tissue. ${ }^{4}$ The proportion of muscle tissue for fibrous components varies approximately from $30 \%$ in the internal os to $6 \%$ in the external os, with more fibrous tissue concentration in the inferior portions of the cervix. ${ }^{5}$ Other cervix components are proteoglycans and glycosaminoglycans forming the extra cellular matrix, fybronectin and elastin. 6

Muscle fibers grouped in a circle surrounding the cervical canal covered by conjunctive tissue would originate a more fragile external os and a well developed internal os which could have a protective role to maintain the embryo. The resistance of these structures should be surpassed during cervical ripening, i.e., before labor induction.

The study of cervix resistance reduction during pregnancy determined that biochemical factors caused its physical alterations. 7 To identify these biochemical factors, pregnant rats' cervices were ripened with progesterone, stradiol, and relaxin. Then it was determined that estrogen caused cervix dilation and relaxin reduced collagen concentration. Therefore, the conclusion is that the association of the two hormones would cause cervical changes very similar to physiological ones. 8

During parturition a dissociation process in the cervix occurs without dissolving the collagen fibers of the extra cellular matrix to enable the passage of the newborn and the cervix coming back to normal following pregnancy. This is probably due to changes in the conjunctive tissue with cohesion reduction between the different types of collagens forming the cervix and the increase of hyaluronic acid. Following birth water reabsorption occurs and the conjunctive tissue structure goes back to normal. Other elements also seem to be involved such as specific colagenase and polymorphonuclear leucocytes. 6

It is known that the cervix is metabolically active during cervical ripening and passive during labor. 9 This is due to the many changes, some still under study, related to the increased production of hyaluronic acid regulating the production of interleukin 1-beta, tumoral necrosis factor-alpha and interleukin- 8 by uterine fibroblasts. These when stimulated by interleukin 1-Alpha and by hyaluronic acid could release the hyaluronidase in the cervix. 10

The conjunctive tissue of the cervix is loose with a great volume of water in its composition. This water is not free, it is solvation water linked to proteins and glycosaminoglycans including hyaluronic acid (non-sulphated glycosaminoglycan). ${ }^{11}$ As related to the cervix, it has been demonstrated that the increase in the levels of hyaluronic acid as pregnancy evolves is statistically different from pre-term, at term and during labor, 12 reinforcing the value of its role in the series of events involved in cervical ripening.

Physical properties of the cervix depend upon the relationship between collagen fibers and glycosaminoglycan molecules. In the beginning of parturition there is a reduction in the concentration of collagen and other glycosaminoglycans concurrently with an increase in the concentration of hyaluronic acid which then becomes the prevalent glycosaminoglican in the cervical portion of the uterus. Hyaluronic acid is found in high concentrations in the cervix prior to the increase of $\mathrm{PgE}_{2}$, relaxin and progesterone antagonists. 10 Hyaluronic acid degradation is dependent on hyalurondase following the linking of this enzyme with CD44 receptors, hydrolyzing the molecule in great fragments thus controlling hydration of this conjunctive tissue because of the high affinity of these fragments with water. 10

There are significant changes in hyaluronidase activity and in the concentration and molecular weight of the hyaluronic acid in the cervical mucus related to the concentration increase of hyaluronic acid in the first stage of labor and increase of hyaluronidase activity one week prior to labor and during the first stage of labor, and decrease of molecular weight of the hyaluronic acid during the first stage of labor. These changes could be associated to the physiological adjustment of cervical ripening. 13

Among different biochemical changes in the cervix the capability of producing prostaglandines, initially studied in vitro, should be mentioned. There is a production increase at the end of pregnancy as well. Such demonstration is important to the extent that prostaglandins are also active in the process of cervical dilation. 14

\section{Methods of cervix ripening}

Considering cervix uterus characteristics different methods have been used to improve its conditions prior to labor induction. In general they could be divided into biochemical or mechanical, respectively corresponding to the use of pharmacological substances through different ministration ways or to the use of devices crossing the cervical canal. For that reason, two other methods described, nipple stimulation and membranes stripping, could be considered mixed in the classification by mechanism of action.

Nipple stimulation has been suggested as a 
method for cervical ripening and labor induction not requiring medical intervention, at no cost and no risks of complications. Six randomized studies, involving 719 women using and not using this type of intervention have demonstrated that after 72 hours there were fewer pregnant women not in labor in the group using nipple stimulation and a lower risk for post-partum hemorrhage. Method of delivery and meconium elimination were similar in both groups. These data should be carefully assessed for there are few comparative studies. Nevertheless, this is a not contra indicated method for low risk pregnancies, which needs more controlled studies to evaluate its safety for high risk pregnancies and efficacy in general. 15

Membrane stripping was initially suggested in 1810 by James Hamilton for labor induction. It is a very often used simple technique with few comparative studies until recently. Membranes stripping correspond to digital separation by vaginal exam of the ovular membranes of the lower segment of the uterus through a circular movement. Evaluation of results from 19 controlled studies determined that this intervention was associated to a reduced rate of post-term pregnancies, i.e. beyond 41 weeks, less need for the application of other induction methods, no increased risk for premature rupture of membranes or neonatal infection. 16

Among the biochemical methods there are the drugs involved in collagen degradation and or myometrical contractility onset, i.e. relaxin, estrogens, corticosteroids, oxytocin, prostaglandins, mifepristone and hyaluronidase.

Relaxin is a protein formed by two aminoacid chains and its role in pregnancy and parturition is not clear yet. Involvement in the process of cervical ripening has been questioned since the 50's. Because of the difficulty of using human relaxin, bovine or porcine relaxin were used instead, with controversial results and the risk of sensibilization. Currently with recombining DNA techniques, human relaxin can be synthesized and better studied. The conclusion is that the substance could promote cervical changes and should not be associated to uterine hyper stimulation considering it has a possible inhibiting effect to myometrial contractility. Controlled studies with a total of 267 pregnant women have indicated that there was improvement of the uterine cervix condition, there were no cases of uterine hyper stimulation and $\mathrm{C}$-section rates were the same for women receiving treatment and women receiving placebo. 17

Experimental studies in lambs indicated an increase of estrogen concentration in serum and progesterone reduction before parturition onset. The hy- pothesis is that these changes would stimulate the production of prostaglandins, then favoring the onset of labor. A systematic review determined the lack of data leading to definitive conclusions, nevertheless the studies analyzed do not indicate differences between women using estrogens for cervical ripening when compared to women using placebo. 18

The role of corticosteroids in the labor process is not well known yet. Classical experimental studies indicated the value of cortisol secretion by the fetal adrenal gland to the onset of parturition in lambs. In addition, glycocorticoids infusion in lamb's fetus has induced preterm delivery. Nevertheless, there is no effect of labor onset in post-term pregnant women using corticosteroids. ${ }^{19}$ Some studies tried to show that the use of glycocorticoids in post-term pregnant women in the intra-amniotic space could induce labor, nevertheless there are no clinical trials to compare these results with other methods for cervical ripening or labor induction. 20

As for oxytocin it is known that when used intravenously, it encourages and coordinates uterine activity, affecting myometrial muscles and increasing the frequency and intensity of contractions which in turn will cause cervical changes. This mechanism is more easily obtained in term or post-term pregnancies due to the physiological increase of endogenous estrogen at this time, which promotes the stimulation of oxytocin receptors thus facilitating the action of exogenous oxytocin. 21

Oxytocin has been safely used for decades and the results are satisfactory for labor induction. The proposal to use in women with unfavorable cervical conditions is through serial induction sessions of 10 to 12 hours a day, followed by rest, with duration of three to four consecutive days. Nevertheless, different studies have demonstrated that its efficacy for cervical ripening is lower than other more specific methods. Comparing oxytocin results with other methods of cervix ripening /induction, results were less favorable for women using oxytocin only, with lower vaginal delivery rates and longer induction time. ${ }^{22,23}$

\section{Prostaglandins}

Many studies attempted to determine the role of prostaglandines $(\mathrm{Pg})$ in the uterus cervix and which of them would cause effects similar to physiological processes. As a result, it has been determined that $\mathrm{PgF}_{2 \alpha}$ would be the one causing cervical changes more similar to physiological ones. 24 Afterwards with the development of $\mathrm{PgE}_{2}$ in form of a gel for cervical use, it became the choice Pg for cervical 
ripening and labor induction in developed countries. In practice, clinical use in developing countries has never been consistent, because of the high cost and thermolability making commercialization and storage difficult.

Prostaglandins in general, specially the $\mathrm{PgE}$, have been extensively studied for clinical use, for cervical ripening and labor induction. $22,25,26$ Nevertheless both the synthetic and natural ones, although they have been determined to be efficacious and safe, do have some inconveniences, such as stimulating uterine contractility when the initial aim is restricted to cervical change, use cannot be interrupted even in the occurrence of an undesirable effect, are associated to hyper stimulation of the uterus are not readily accessible in Brazil and are contraindicated in women with prior C-Section scars.

Mysoprostol, a methyl analogue PgE1 has become the choice prostaglandin of more recent studies, for many reasons: it is cheaper, easy to store because of thermo stability, can be used many ways with efficacy. As for the main undesirable effect, uterus hyper stimulation, the use of low doses $(25 \mathrm{mcg})$ every four to six hours has been determined to be safe, reducing this effect.27-29 In addition, this is the only prostaglandin really available in the domestic market.

\section{Mifepristone}

Mifepristone or RU 486 is a progesterone antagonist used since 1988 especially in Western Europe. It was initially developed as an abortifacient. It causes dilation of the cervical canal and increases uterine contractility, thus reducing the required doses of prostaglandin to expel the embryo. It has been recently used in cases of post-term pregnancies in comparison with a group receiving placebo. This study involved 180 of which 97 used mifepristone, with a statically significant difference related to labor time, the mean oxytocin dosage used and the occurrence of vaginal delivery in the group using the medication. Bishop score did not vary following the use of RU486 or placebo. The conclusion is that its action in cervix ripening is modest but it does reduce the need of other drugs to induce labor. 30

It probably is a new field for future research on cervical ripening and labor induction in viable pregnancies. A systematic review concluded that data are insufficient to assess the efficacy of mifepristone for cervical ripening and there are no comparative studies of this method with others such as, for example prostaglandins. Nevertheless, when compared to placebo there is evidence that the risk for $\mathrm{C}$-section is lower for women treated with this substance. 31

\section{Hyaluronidase}

Hyaluronidase was used for the first time by Berlingeri in 195932 in pregnant women with spastic cervix demonstrating effectiveness in 17 of the 20 cases evaluated. With the same purpose, i.e. to improve spastic cervix during labor, 82 pregnant women also used hyaluronidase resulting in shorter labor time compared to the control group of 54 pregnant women, specially primaparous. ${ }^{33}$ Its use at the onset of labor was responsible for statistically significant results related to reduction of labor time in women in their first pregnancy. 34 Intracervical injections were used as well to ripen the cervix among pregnant women with unripe cervices prior to labor induction with promising results. 32

Hyaluronidase is a local action enzyme prepared from bovine testes, which hydrolyzes hyaluronic acid breaking the glycosamidic link between the $\mathrm{C} 1$ of glycosamine and $\mathrm{C} 4$ of glycuronic acid. This reaction temporarily reduces cellular cement viscosity, promoting the diffusion of injected fluids, transudates or exudates, helping its absorption. 13 Mechanism of action basically consists in the depolimeryzation of the conjunctive components of the cervix (collagen, hyaluronic acid and condroitine), reducing cellular adhesion of collagen of the cervix, causing softening and effacing and changing the Bishop Score. 35,36

Hyaluronidase is considered a method restricted to cervix ripening for it does not onset labor. Therefore it is the closest method of what would theoretically be the ideal method. It is easy to apply, cost is low and is available in the domestic market, can be used out of the hospital before admittance to induce labor. There are no contraindications for women with prior $\mathrm{C}$-sections, and can be the right choice for cervical ripening in this situation.

\section{Mechanical methods}

In the second group, mechanical methods which were the first methods developed to ripen the cervix or induce labor can be found. Among them there are different types of catheters (including the Folley catheter) and laminaria introduced in the cervical canal or extra-amniotic space.

Mechanical methods were never totally abandoned but extensively replaced by pharmacological 
methods in the last decades. There is a recent trend of reintroducing it for clinical use because of some advantages and availability of sterile devices, controlling one of the principal contraindications, infection. Potential advantages of mechanical methods in comparison with pharmacological ones include easy conservation, low cost and less side effects. Nevertheless, there is contraindication of its use in pregnant women with low inserted placentas, with premature rupture of membranes and as it was already stated there could be higher incidence of puerperal infection and discomfort among users of these methods. 37

A systematic review including 45 studies using mechanical methods in general compared with placebo/no treatment in addition to mechanical methods compared to prostaglandins, concluded that data are insufficient to evaluate the occurrence of vaginal delivery within 24 hours when compared with prostaglandins (intracervical, intravaginal or oral). When compared with oxytocin as a stand alone agent, mechanical methods also reduce the risk of performing a C-section. It further determines the lack of scientific basis for the use of extra-aminiotic infusions associated to mechanical methods. 37

One of the mechanical methods is laminaria (Laminaria digitata or Laminaria japonica), a seaweed that after dehydration acquires a hygroscopic ability. Prepared in the shape of a baton it can be used as a cervical dilator. Laminaria use has been described since the Eighteenth Century but its use was abandoned due to the risk of infection. In the 70 's with the new sterilization techniques its use was resumed with satisfactory results. 38,39 Mechanism of action depends on the mechanical effect obtained through radial expansion which because it occurs slowly does no lesion the muscle fibers of the cervical canal. It also has a biochemical effect for it causes a foreign body reaction and local release of prostaglandins. 40 Utilization time of laminaria may vary from 12 to 24 hours, nevertheless, because its maximum capacity of diameter increase occurs within approximately 12 hours it would be required to reassess the cervix during this period and replace the laminaria for another larger one when necessary. More recently clinical use for this purpose has been replaced by other more effective methods.

The use of a catheter in the extra-amniotic space occurred the first time in 1853 by Krause quoted by Hamilton ${ }^{41}$ a method named after him. At that time a rigid catheter was used. After that the Foley catheter, a flexible catheter was used to induce labor in women with unripe cervices with $94 \%$ of success. 42 At times this method is still described like the modified Krause method and because it is more acceptable and less risky it has been more utilized that the classically described method.

The mechanism of the Foley catheter is based on the presence of a mechanical factor acting continuously on the cervix and in addition because it separates the chorion from the decidua releasing local prostaglandins. ${ }^{43}$ The use of the Foley catheter associated to intravenous oxytocin demonstrated the same efficacy of the methyl-analogous $\mathrm{E}_{1}$ prostaglandin in multiparous women and better results in primaparous women of the same study. 44 Another clinical trial with over 200 pregnant women demonstrated interesting results comparing prostaglandin $\mathrm{E}_{2}$ with the Foley catheter with similar induction time and labor time but with higher $\mathrm{C}$-section rates in the prostaglandin group. This difference remained significant when a group of nuliparous women was analysed, increasing the understanding that the Foley catheter is an alternative to prostaglandin use. There was no difference on infection events between the groups. 45

Extra-amniotic infusion associated to the Foley catheter for labor induction has traditionally been used. Compared with the infusion of saline solution and $\mathrm{PgE}_{2}$ there was a shorter permanence time with the balloon, less induction time and oxytocin need in the group using prostaglandin, however with no difference related to the type of delivery. 46 As for the method described above, there are still many controversies. A study comparing misoprostol, Foley catheter and the association of the Foley catheter with prostaglandin $E_{2}$ indicated no difference between these three methods of cervical ripening/labor induction. There was only a greater incidence of tachysistole with lower oxytocin need in the group using misoprostol but with no difference related to the type of delivery. Therefore, there is no need to use extraamniotic solution injections (in this case prostaglandin $E_{2}$ ) for results are similar whether or not it is used. 47

Some of advantages of the Foley catheter compared to other methods of cervix ripening and labor induction are: low cost, easy to use and principally the possibility of using it in women with prior C-sections. In Brazil its use is still rather restricted and there are no results of effectiveness studies already published.

\section{Final considerations}

Because of the need and/or indication of the interruption of an at term pregnancy, a question rises: in- 
duction or C-section? This is the question every obstetrician asks when in the face of a pregnant woman with maternal or fetal indication for pregnancy interruption. Even if cervix conditions are favorable, and there is a good prior history of vaginal deliveries only few obstetricians are committed to try a vaginal delivery. Nevertheless, there is no doubt this is the best way to interrupt a pregnancy especially at term pregnancies. And when the cervix is unripe or when there is a previous C-section scar, or when the prognosis of an induction does not seem favorable? Reality is that a great part of these women receive today, as the only option of their obstetricians, an elective C-section. This probably occurs for many reasons going from lack of time of the doctor to follow-up a procedure requiring time and dedication, to the lack of understanding on the part of the pregnant women and family if the induction fails and some time later a $\mathrm{C}$-section becomes necessary.

Unfortunately this is reality in Brazil with problems related to high rates of $\mathrm{C}$-sections; with healthcare services specially private medicine and health insurance companies where women are more at risk of not having vaginal deliveries; and with the public health system where vaginal deliveries occur more frequently when spontaneous. But, when theoretically there is a need for induction the situation is different. Women are generally at the mercy of the opinion of whoever doctor on duty without the right to participate in the decision and not adequately informed.

And why does this happen? Probably this is a multifactored issue with anthropological, cultural and medical aspects. But it also has to do with the gap in the country's development when compared to developed countries, from an economic and scientific viewpoint in relation to pharmacological and mechanical techniques for cervical ripening, especially pharmacological and specifically prostaglandins. These are safely used in European countries 48 but took many decades to be used in Brazil and even today face use restriction. These factors and many others have forced Brazilian obstetricians even in many cases in which induction prognosis is good, choose the C-section.

This causes the need to intervene in medical education, to learn and to teach that vaginal delivery is the best way to end a pregnancy in the majority of situations, and once the risks of each case are evaluated, the best way of delivery should be selected. It is necessary to consider the time one can wait for each baby, for each pregnant woman with some pathological condition and based on the availability of time, propose the best method for ripening an unripe cervix, to directly indicate labor induction or to even establish that when induction prognosis is not good and time is short, the $\mathrm{C}$-section could be the best choice.

Prostaglandins and principally synthetic analogues are and should be for a long time, in the majority of cases, the best options for cervical ripening and labor induction not only for its efficacy and safety but also for the low cost of this procedure. The best regimen is being thoroughly studied, including posology, interval for application and the way of use. This has been changed with time going from the oral to the intra-cervical, vaginal, rectal and presently the more convenient oral and sublingual use. 49

It is important to note that there are absolute and relative contraindications for the use of prostaglandins and the presence of a prior uterus scar is one of the formal contraindications. 28 This situation is very frequent in our country thus requiring other options for cervical ripening followed by labor induction specifically for these cases. In addition to the C-Section, multiparity was associated to a higher risk of uterine rupture when misoprostol was used,50 although this is controversial with other authors advocating the safety of misoprostol for multiparous women.51 Both situations, former C-Section and multiparity, are relatively common conditions for labor induction. Therefore, other methods of cervix ripening and labor induction that are adequate, effective, known and available are needed.

Consequently, the pursue of increasing the options for cases requiring induction in which prostaglandin use is not always the best one, different studies have resumed focusing on mechanical and other pharmacological methods. Therefore, some compared Pgs with the Foley catheter and demonstrated similar and even better results for certain groups of women using the Foley catheter. This made the method, available everywhere, scientifically come back to life and several studies were preformed demonstrating its efficacy, safety without increasing the need of additional substances, for example oxytocin or even prostaglandins in the procedure. 52

A systematic review has concluded that there are no comparable clinical trials for hyaluronidase. 17 Available studies are not randomized comparing this method with other methods in different schemes, resulting in difficulties in determining the best way for clinical use. Only with the accomplishment of new studies with the product, randomized and methodologically rigorous these gaps can be filled and knowledge used in obstetrical practice based on scientific results. 
Another issue to be highlighted and a very attractive one is the possibility of performing cervical ripening out of the hospital, applicable only to low risk pregnancies. This is an issue that has been extensively studied with many potential advantages such as a shorter hospitalization time, more time for cervical ripening in addition to being more convenient and comfortable. 53

Hyaluronidase is a method that although there are few studies assessing outpatient use it seems excellent and convenient for that purpose. It is not disturbing to woman, is easy to apply, acts slowly, is physiologically increased before labor and not associated to labor onset or to any complications in the period of cervical ripening. 13 This way women may undergo serial, daily or alternate day use until cervix ripens for induction. A national study indicated good results when hyaluronidase is used between 38 and 42 weeks in an outpatient basis, where treated women had a higher Bishop score than women receiving placebo when examined after 48 and 96 hours. In these women induction labor time was smaller with a higher occurrence of vaginal delivery. 35

Foley catheter at first sight does not seem to be a good method to be used in an outpatient clinic. This impression is probably because it is indirectly associated to the popular method of catheter induced abortions. Nevertheless there are studies comparing the method in inpatients and outpatients with practically the same results for the two groups. 54

Systematic and scientifically well conducted study of different methods in Brazilian populations should enable their validation and use in the country, as well as to favor and publicize the benefits of induction use as an efficient and safe alternative for cases where required, thus contributing to reduce the high rates of C-Sections 48 that we still have.

\section{Referências}

1. Osis MJD, Padua KS, Duarte GA, Souza TR, Faúndes A. The opinion of Brazilian women regarding vaginal labor and cesarean section. Int J Obstet Ginecol 2001; 75: S59-66.

2. Bishop EH. Pelvic scoring for elective induction. Obstet Gynecol 1964; 24: 266-8.

3. Mastrogiannis DS, Knuppel RA. Labor induced using methods that no involve oxytocin. Clin Obstet Gynecol 1995; 38: 259-66.

4. Minamoto T, Arai K, Hirakawa S, Nagai Y. Immunohistochemical studies on collagen types in the uterine cervix in pregnant and nonpregnant states. Am J Obstet Gynecol 1987; 156: 138-44.

5. Johnson JR, Iams JD. Cervical incompetence. In: Rose BD, editor. Up to date. Wellesley, MA; 2004.

6. Leppert PC. Anatomy and physiology of cervical ripening. Clin Obstet Gynecol 1995; 38: 267-79.

7. Harkness MLR, Harkness RD. Changes in the physical properties of the uterine cervix of the rat during pregnancy. J Physiol 1959; 148: 524-47.

8. Cullen BM, Harkness RD. The effect of hormones on the physical properties and collagen content of the rat's uterine cervix. J Physiol 1960; 152: 419-36.

9. Poma PA. Cervical ripening. A review and recommendatios for clinical practice. J Reprod Med 1999; 44: 657-68.

10. Kobayashi H, Terao T. Hialuronic acid-specific regulation of cytokines by human uterine fibroblasts. Am J Physiol 1997; 273: 151-9.

11. El Marandny E, Nakayama N, Kobayashi H, Hossain B, Khatun S,Liping S, Kobayashi T, Terao T. The role of hyaluronic acid as a mediator and regulator of cervical ripening. Human Reprod 1997; 12: 1080-8.
12. Kobayashi H, Sun GW, Tanaka Y, Kondo T, Terao T. Serun hialuronic acid levels during pregnancy and labor. Obstet Gynecol 1999; 93: 480-4.

13. Obara M, Hirano H, Ogawa M, Tsubaki H, Hosoya N, Yoshida Y, Miyauchi S, Tanaka T. Changes in molecular weight of hyaluronan and hyaluronidase activity in uterine cervical mucus in cervical ripening. Acta Obstet Gynecol Scand 2001; 80: 492-6.

14. Ellwood DA, Mitchell MD, Anderson ABM, Turnbull AC. The in vitro production of prostanoids by the human cervix during pregnancy: preliminary observations. Br J Obstet Gynaecol 1980; 87: 210-4

15. Kavanagh J, Kelly AJ, Thomas J. Breast stimulation for cervical ripening and induction of labour. Cochrane review. The Cochrane Library 2004 (1). [Update Software].

16. Boulvain M, Stan C, Irion O. Membrane sweeping for induction of labour. Cochrane review. The Cochrane Library 2004 (1) [Update software].

17. Kelly AJ, Kavanagh J, Thomas J. Relaxin for cervical ripening and induction of labour. Cochrane Review. The Cochrane Library 2004 (1). [Update software].

18. Thomas J, Kelly AJ, Kavanagh J. Oestrogens alone or with amniotomy for cervical ripening and induction of labour. Cochrane review. The Cochrane Library 2004 (1). [Update software].

19. Matti JKG, Horobin DF, Branley PS. Induction of labour in sheep and in humans by single doses of corticosteroids. Br Med J 1973; 2: 149-51.

20. Kavanagh J, Kelly AJ, Thomas J. Corticoteroids for induction of labour. Cochrane review. The Cochrane Library 2004 (1). [Update software]. 
21. Satin AJ, Leveno KJ, Sherman ML, Mcintire DD. Factors affecting the dose response to oxytocin in labor stimulation. J Obstet Gynecol 1992; 166: 1260-1.

22. Sanchez-Ramos L, Kaunitz AM, Del Valle GO, Delke I, Schroeder PA, Briones DK. Labor induction with the prostaglandin E1 methyl analogue misoprostol versus oxytocin: a randomized trial. Obstet Gynecol 1993; 81: 332-6.

23. Aquino MMA, Cecatti JG. Misoprostol versus oxytocin for labor induction in term and post term pregnancy. Randomized controlled trial. São Paulo Med J 2003; 121 : $102-6$.

24. Rath W, Theobald P, Kühnle H, Kuhn W, Hilgers H, Weber L. Changes in collagen content of the first trimester cervix uteri after treatment with prostaglandin F2a gel. Arch Gynecol 1982; 231: 107-10.

25. Bugalho A, Bique C, Machungo F, Faúndes A. Low-dose vaginal misoprostol for induction of labor with a live fetus. Int J Gynaecol Obstet 1995; 49: 149-55.

26. Wing DA, Rahall A, Jones MM, Goodwin TM, Paul RH. Misoprostol: an effective agent for cervical ripening and labor induction. Am J Obstet Gynecol 1995; 172: 1811-6.

27. Wing DA, Paul RH. A comparison of differing dosing regiments of vaginally administered misoprostol for preinduction cervical ripening and labor induction. Am J Obstet Gynecol 1996; 175: 158-64.

28. ACOG (American College of Obstetrician and Gynecologists). ACOG Committee Opnion. Induction of labor with misoprostol. Int J Gynecol Obstet 2000; 69: 77-8.

29. Blanchard K, Clark S, Winikoff B, Gaines G, Kabani G, Shannon C. Misoprostol for women's health: a review. Obstet Gynecol 2002; 99: 316-32.

30. Wing DA, Fassett MJ, Mishell DR. Mifepristone for preinduction cervical ripening beyond 41 weeks' gestation: a randomized controlled trial. Obstet Gynecol 2000; 96: 543-8.

31. Neilson JP. Mifepristone for induction of labour. Cochrane review. The Cochrane Library 2004 (1) 2004. [Update software].

32. Spallicci MDB, Chiea MA, Albuquerque PB, Singer JM, Bittar RE, Zugaib M. Ação da hialuronidase na maturação do colo uterino em gestações a termo. Rev Ginecol Obstet 2000; 11: 93-102.

33. Green PS. Intracervical injection of hyaluronidase: effect on dilatation and length of labor. Am J Obst Gynecol 1967; 99: 337-40

34. Gupta T, Verma NK, Sood A. Effects of intracervical injection of hyaluronidase in primigravidae during labor. J Indian Med Assoc 1993; 92: 47-8.

35. Li W, Li Z, Ha KW. Effect of hyaluronidase on cervical ripening. Chin Med J Engl 1994; 107: 552-3.

36. Kavanagh J, Kelly AJ, Thomas J. Hyaluronidase for cervical priming and induction of labour. Cochrane review. The Cochrane Library 2004 (1). [Update software].

37. Boulvain M, Kelly A, Lohse C, Stain C, Irion O. Mechanical methods for induction of labour. Cochrane review. The Cochrane Library 2004 (1) [Update software].
38. Cross WG, Pitkin RM. Laminaria as an adjunct in induction of labor. Obstet Gynecol 1978; 51: 606-8.

39. Kazzi GM, Bottons SF, Rosen MG. Efficacy and safety of laminaria digitata for preinductin ripening of the cervix. Obstet Gynecol 1982; 60: 440-3.

40. Kramer J, O'Brien WF. Mechanical methods of cervical ripening. Clin Obstet Gynecol 1995; 38: 680-4.

41. Hamilton J. Historical review of British obstetric and gynecology: 1800-1950. Edinburg: Livingstone; 1954. 18001950.

42. Embrey MP, Mollison BG. The unfavorable cervix and induction of labor using a cervical balloon. J Obstet Gynaecol Br Cwlth 1967; 74: 44-8.

43. Kierce MJ, Thiery M, Parewijck W. Chronic stimulation of uterine prostaglandin synthesis during cervical ripening before the onset of labor. In: Prostaglandins 1983; 25: 671-82

44. Abramovici D, Goldwasser S, Mabie BC, Mercer BM, Goldwasser R, Sibai BM. A randomized comparison of oral misoprostol versus Foley catheter and oxytocin for induction of labor at term. Am J Obstet Gynecol 1999; 181: 1108-12.

45. Guezzi F, Massimo F, Raio LN, Balestreri D, Bolis P. Extra-amniotic Foley catheter and prostaglandin E2 gel for cervical ripening at term gestation. Eur J Obst Reprod Biol 1967; 99: 337-40.

46. Sherman DJ, Frenkel E, Pansky M, Caspi E, Bukovsky I, Langer R. Balloon cervical ripening with extra-amniotic infusion of saline or prostaglandin E2: a double blind, randomized controlled study. Obstet Gynecol 2001; 97: 375-80.

47. Greybush M, Singleton C, Atlas RO, Balducci J, Rust OA. Preinduction cervical ripening techniques compared. J Reprod Med 2001; 46: 11-7.

48. Hofmeyer GJ, Gulmezoglu AM. Vaginal misoprostol for cervical ripening and induction labour. Cochrane review. The Cochrane Library 2004 (1) [Update software].

49. Tang OS, Schweer H, Seyberth HW, Lee SWH, Ho PC. Pharmacokinetics of different routes of administration of misoprostol. Human Reprod 2002; 17: 332-6.

50. Mathews JE, Matai M, George A. Uterine rupture in a multiparous woman during labor induction with oral misoprostol. Int J Gynaecol Obstet 2000; 68: 43-4.

51. Bique C, Bugalho A, Bergstron S. Labor induction by vaginal misoprostol in grand multiparous women. Acta Obstet Gynecol Scand 1999; 78: 198-201.

52. Sullivan CA, Benton LW, Roach H, Smith LG Jr, Martin $\mathrm{RW}$, Morrison JC. Combining medical and mechanical methods of cervical ripening. Does it increase the likelihood of successful induction of labor? J Reprod Med 1996; 41: 823-8.

53. Sawai SK, O'Brien WF. Outpatient cervical ripening. Clin Obstet Ginecol 1995; 38: 301-9.

54. Sciscione AC, Muench M, Pollock M, Jenkins TM, TildoBurton J, Colmorgen GH. Transcervical Foley catheter for preinduction cervical ripening in an outpatient versus inpatient setting. Obstet Gynecol 2001; 98: 751-6. 